\title{
Effects of Deer Settling Stimulus and Deer Density on Regeneration in a Harvested Southern New England Forest
}

\author{
Kevin J. Barrett ${ }^{1,2}$ and Oswald J. Schmitz ${ }^{1}$ \\ ${ }^{1}$ School of Forestry \& Environmental Studies, Yale University, 370 Prospect Street, New Haven, CT 06511, USA \\ ${ }^{2}$ NEON, Inc., 1685 38th Street, Suite 100, Boulder, CO 80301, USA
}

Correspondence should be addressed to Kevin J. Barrett; kbarrett@neoninc.org

Received 22 May 2013; Accepted 3 August 2013

Academic Editor: Friedrich Reimoser

Copyright (C) 2013 K. J. Barrett and O. J. Schmitz. This is an open access article distributed under the Creative Commons Attribution License, which permits unrestricted use, distribution, and reproduction in any medium, provided the original work is properly cited.

\begin{abstract}
Elevated deer densities have led to reports of forest regeneration failure and ecological damage. However, there is growing evidence that the biophysical conditions of a forest that make it attractive to deer may be a contributing factor in determining browsing levels. Thus, an understanding of settling stimulus - how attractive an area is to deer in terms of food-independent habitat requirementsis potentially important to manage deer browsing impacts. We tested the settling stimulus hypothesis by evaluating the degree to which thermal settling stimulus and deer density are related to spatial variation in browsing intensity across different forest harvesting strategies over the course of a year. We determined if deer were impacting plant communities and if they resulted in changes in plant cover. We quantified the thermal environment around each harvest and tested to see if it influenced deer density and browsing impact. We found that deer had an impact on the landscape but did not alter plant cover or diminish forest regeneration capacity. Deer density and browse impact had a relationship with thermal settling stimulus for summer and fall months, and deer density had a relationship with browse impact in the winter on woody plants. We conclude that thermal settling stimulus is an important predictor for deer density and browsing impact.
\end{abstract}

\section{Introduction}

The slowing or failure of the regeneration of high value timber species in the northeastern USA is often attributed to high white-tailed deer (Odocoileus virginianus) abundances [1,2]. In particular, above threshold densities of 10 to 15 deer $\mathrm{km}^{-2}$, deer are reported to alter forest composition via selective browsing of woody plant species such as eastern hemlock (Tsuga canadensis), red maple (Acer rubrum) sprouts, and Rubus spp. [1, 3-5]. Heavy browsing may in turn cause forest regeneration failure and decreased vertical structural complexity of forest stands that may impact wildlife habitat and ecosystem functions such as nutrient mineralization rates [610]. Selective browsing by highly abundant deer populations may also interact with forest management, causing areas to entrain into altered stable states [11] and creating savannahlike areas dominated by ferns, grasses, and sedges that inhibit forest regeneration [1].

Nevertheless, deer density and selective browsing alone may not always explain spatial and temporal variation in vegetation impacts $[12,13]$. Instead, available forage in relation to settling stimulus-how attractive an area is in terms of the food-independent habitat requirements of deer, such as thermal and hiding cover, edge effect, and level of disturbance [14-19] — may be a contributing factor determining levels of browsing impact $[13,17,20,21]$. Because deer must manage tradeoffs between eating and maintaining thermal homeostasis $[22,23]$, high deer impacts may occur wherever areas that supply high forage production (such as sites that have recently undergone timber harvest) are juxtaposed with favorable thermal cover [14-19]. Accordingly, deer impacts may be alleviated via forest management strategies that mediate settling stimulus and thereby make economically valuable forest stands less attractive to deer $[1,19,24]$. To this end, forest harvesting strategies that consider settling stimulus may reduce a stand's predisposition to heavy browsing by deer $[15,19]$. Although this is a well-tested hypothesis for European ungulates such as roe deer (Capreolus capreolus), this remains an untested hypothesis for white-tailed deer. The objective of this study was to experimentally test the extent to which thermal settling stimulus, determined by the thermal 
environment, and deer density determine spatial variation in browsing intensity. We quantified the effects of thermal settling stimulus and deer activity density under different forest harvest strategies over the course of a year.

\section{Materials and Methods}

2.1. Study Area. We conducted our study in the 3213 ha YaleMyers Forest (YMF) in northeastern Connecticut $\left(41^{\circ} 57^{\prime} \mathrm{N}\right.$, $\left.72^{\circ} 28^{\prime} \mathrm{W}\right)$. YMF is a mixed hardwood forest dominated by red oak (Quercus rubra), black oak (Q. velutina), red maple, sugar maple (Acer saccharum), black birch (Betula lenta), yellow birch (B. alleghaniensis), white ash (Fraxinus americana), pignut hickory (Carya glabra), and eastern hemlock, with interspersed white pine (Pinus strobus) stands. The understory is comprised of a diverse community of shrubs and forbs, including mountain laurel (Kalmia latifolia), hayscented fern (Dennstaedtia punctilobula), Canada mayflower (Maianthemum canadense), wild sarsaparilla (Aralia nudicaulis), star flower (Trientalis borealis), and Rubus species. State parks, forests, and large private forest holdings surround the forest, making it a large habitat island within a semiurban landscape that fostered deer densities between 8 and 10 per $\mathrm{km}^{2}$ in 1995 [25].

YMF implemented a variety of forest harvesting treatments to compare their efficacy to regenerate oak. We superimposed our study on this harvested landscape and evaluated several shelterwood ( $n=6$ replicates), crown thinning ( $n=4$ replicates), and reserve $(n=5$ replicates) harvesting strategies to determine if and how these strategies influence deer herbivory patterns. Shelterwood harvests removed 60$90 \%$ of the original basal area (BA), leaving $4.5-13.8 \mathrm{~m}^{2} \mathrm{ha}^{-1}$ of BA. Slash was not treated and was scattered along the forest floor. These harvests promote high forage production, have abundant edge habitat, and are designed to regenerate a new cohort of oak. Crown thinning harvests removed $25-35 \%$ of the original BA, leaving $18.4-20.7 \mathrm{~m}^{2} \mathrm{ha}^{-1}$ of BA. These harvests had lower forage production and less slash on the forest floor and typically result in a pulse of understory regeneration that is later shaded out by the remaining canopy. The reserves are managed for purposes other than timber harvesting, including education and research, and thus serve as experimental controls because no harvesting has taken place within them. These areas typically have little to no forage production.

2.2. Herbivory Sampling. We selected areas that were harvested between 2008 and 2010. Within each harvesting strategy replicate (hereafter, replicate), we paired deer exclosures and open plots to evaluate herbivory patterns. Plot locations within the harvested sites were selected to control for site conditions such as slope, distance from the nearest edge, and understory plant communities. The fenced exclosure plots, made of welded wire fencing were $25 \mathrm{~m}^{2} \times 1.5 \mathrm{~m}$ tall. We did not detect evidence of deer presence within the exclosure after the fences were constructed. The open plots were also $25 \mathrm{~m}^{2}$ and allowed deer to forage freely within them. The paired plots were constructed in March and April of 2011.
We sampled herbivory patterns once a month between May 2011 and March 2012. We did not sample in December 2011 for logistical reasons. Within each plot, we sampled four $1 \mathrm{~m}^{2}$ subplots for percent cover and browse impact. Subplots were located at the corners of the open and exclosure plots, following Rutherford and Schmitz [13]. The subplots were delineated with PVC sampling squares. We estimated percentage of the ground covered by hardwoods, conifers, shrubs, and forbs that were less than $1.2 \mathrm{~m}$ tall, which is within the optimum height range for deer browse [26, 27]. We calculated browse index, a relative measurement of browsing impact $[28,29]$, as the ratio of browsed terminal twigs relative to total terminal twigs on a plant for every species encountered below a height of $1.2 \mathrm{~m}$. We considered a plant to be browsed by deer when the apical bud was missing and there were remnants of bark strips. We noted an other evidence of browsing impact, such as bark fraying, flower removal, and stem damage for each subplot. We calculated browse indices for each plant group (conifer, hardwood, shrub, and forb). We averaged the individual subplot values for browse index and percent cover to obtain a single estimate for each replicate exclosed and open plot pair.

2.3. Deer Activity Density. We estimated an index of local deer activity and thus potential herbivory pressure, in March 2011 and once per month thereafter from May 2011 through February 2012 within each replicate using deer pellet group counts $[25,30,31]$. Although deer pellet transects have been criticized as not being a direct indicator of deer density, they are a useful and logistically feasible method for indicating the relative density and use preferences of animals among different habitats $[32,33]$. Therefore, these estimates explained the relative use of different harvest strategies by deer, giving us an index of their activity density. We implemented four $20 \mathrm{~m} \times 1 \mathrm{~m}$ linear transects within each replicate. We cleared all deer pellets from the transects as they were tallied, counted the number of newly deposited deer pellet groups per month, and estimated local deer activity density as [30]

$$
\text { Deer } \mathrm{km}^{-2}=x \times 500 \times \frac{100}{y} \times 13 \text {, }
$$

where $x$ is the average number of pellet groups per transect, 500 is the number of transects per hectare, 100 is the number of hectares in a square kilometer, $y$ is the number of days since leaf fall (for March 2011 calculations) or the last time the transect was run (for May 2011 through February 2012 calculations), and 13 is the average number of pellet groups per deer per day [25]. There was no long-term snowpack during the deer activity density sampling period; therefore, no pellets were missed due to being buried in snow. We assumed leaf fall to be 15 October 2010 based on October 2011 observations.

2.4. Thermal Settling Stimulus Estimation. We evaluated the effects of the thermal environment and hence quantified thermal settling stimulus on deer browsing by estimating realized thermal energy exchange (net heat gained or lost by the animal, $T E$ ) within each replicate and surrounding cover 
types (classified as open, hardwood, mixed hardwood, and conifer). High positive TE values indicate high heat gain by deer, more negative TE values indicate that high heat loss by deer, and $T E$ values near zero indicate the environment is thermally neutral for deer. We estimated TE for each harvest in March 2011 and monthly from May 2011 through February 2012 , using the equation for heat flux $[22,34]$ :

$$
T E=M+Q_{\mathrm{abs}}-\gamma \varepsilon T_{r}^{4}-h_{c}\left(T_{r}-T_{a}\right)
$$

where TE is the net heat gained or lost by the animal $\left(\mathrm{Wm}^{-2}\right)$, $M$ is the metabolic heat produced by the animal $\left(\mathrm{Wm}^{-2}\right)$, $Q_{\mathrm{abs}}$ is the solar radiation absorbed by the animal $\left(\mathrm{Wm}^{-2}\right)$, $\gamma$ is the Stefan-Boltzmann constant $\left(\mathrm{Wm}^{-2 \circ} \mathrm{K}^{-1}\right), \varepsilon$ is the emissivity of the animal's surface (0.97), $T_{r}$ is the animal's fur temperature $\left({ }^{\circ} \mathrm{K}\right), T_{a}$ is the ambient air temperature $\left({ }^{\circ} \mathrm{K}\right)$, and $h_{c}$ is the convection coefficient $\left(\mathrm{Wm}^{-2 \circ} \mathrm{K}^{-1}\right)$. We calculated $M$ as abW $\mathrm{a}^{0.75} / 2.11$, such that $a$ is a constant depending on season ( winter $=1.9$, spring $=2.0$, summer $=3.66$, and fall $=3.0[35]$ ), $b$ is a constant (1.8) that refers to deer activity [22, 23], $W$ is the average mass of the deer (assumed to be $135 \mathrm{~kg}$ ), and 2.11 is the animal's surface area. We calculated $T_{r}$ as $6.559+0.944 T_{a}$ [36] where $T_{a}$ is the ambient air temperature. We calculated $h_{c}$ as $5.5 V_{z^{0.5}}$ where $V_{z}$ is the wind speed at height $z$ above the ground. We calculated the solar radiation absorbed as (see [22])

$$
Q_{\mathrm{abs}}=a z S+0.5(a s+a r(S+s))+\varepsilon \gamma c\left(0.5 T_{a}^{4}+0.5 T_{v-g}{ }^{4}\right),
$$

where $a$ is the absorptivity of a deer's surface for shortwave radiation (assumed to be 0.74 ), $z$ is the fraction of the deer's surface area exposed to shortwave radiation (assumed to be 0.185 ; average of the values when the animal is parallel and perpendicular to the suns path), $S$ is direct shortwave radiation $\left(\mathrm{Wm}^{-2}\right), s$ is diffuse shortwave radiation (calculated as $\left.0.1 \mathrm{~S}, \mathrm{Wm}^{-2}\right), r$ is the environment's reflectivity of shortwave radiation (assumed to be 0.2 ), $c$ is a constant describing the cover type ( 1 for open, 1.19 for hardwood, 1.24 for mixed hardwood, and 1.28 for conifer), and $T_{v-g}$ is the ground temperature. We measured air and ground temperatures, wind speed, and direct shortwave radiation in each replicate and surrounding cover type once a month at each replicate. We measured wind speed and air temperature using a digital anemometer (La Crosse Technology, La Crosse, WI), ground temperature with a pocket digital thermometer (Taylor, Oak Brook, IL), and direct shortwave radiation with a light meter (General, New York, NY). We made biophysical measurements for each hour between 0800 and 1600 hours in each month, and averaged the values to obtain one representative measurement for the month.

2.5. Data Analysis. We tested for deer impacts on vegetation (based on browse index and percent cover) using mixed models repeated-measures analysis of variance (ANOVA) with harvesting strategies, exclosure presence, and the month sampled as fixed effects and plot identity as a random effect, allowing us to account for correlation due to the repeated monthly measures of each plot [37]. Browse index and percent cover data were arcsine square root transformed to meet normality assumptions. We constructed our models in the $\mathrm{R}$ statistical package ( $\mathrm{R}$ Version 2.12.1, http://www.R-project.org, accessed 10 January 2011). We used Tukey's procedure on all significant effects $(P \leq 0.05)$ to determine significant separation of means $(P \leq 0.05)$.

We calculated average air and ground temperatures, wind speed, and direct shortwave radiation for each harvest strategy by season (spring, summer, fall, and winter). We used these values in (2) to estimate TE by harvesting strategy and cover type for each season of the year. We defined spring as February 1st through April 30th, summer as May 1st through August 31st, fall as September 1st through October 31st, and winter as November 1st through January 31st.

We addressed how the thermal environment within the vicinity of a harvest site affects settling stimulus. We used ArcGIS v10 (ESRI, Redlands, California, USA) to create a $500 \mathrm{~m}$ buffer around each site (see [12]) and calculate the percentage of each surrounding cover type within the buffer. We also calculated the percentage of the area that was harvested within the buffer. We multiplied each percentage of surrounding cover type and harvested area by its respective $T E$ estimate to obtain an indexed $T E$ value. We then summed all of the indexed values to obtain an overall index of thermal settling stimulus for each replicate. Using regression analysis in $\mathrm{R}$, we regressed local deer activity density on thermal values to determine if the thermal environment could explain variation in local deer abundance. We regressed browse index on thermal values to assess if thermal settling stimulus could explain variation in deer browsing patterns. Finally, we regressed browse index on local deer activity density to determine if estimated deer activity densities could explain variation in deer browsing patterns. We used AIC values to determine if linear, polynomial, or exponential regression models provided the best fit. Models were deemed highly significant when $P \leq 0.05$ and moderately significant when $0.05<P \leq 0.10$.

\section{Results}

Average measured air temperatures $\left({ }^{\circ} \mathrm{C}\right)$ across YMF for the summer, spring, fall, and winter were $23.78 \pm 1.33$ (1SE), $5.30 \pm 0.64$ ( $1 \mathrm{SE}), 12.23 \pm 1.24(1 \mathrm{SE})$, and $4.67 \pm 0.36(1 \mathrm{SE})$, respectively. Estimated local activity density indices (deer $\left.\mathrm{km}^{-2}\right)$ indicated that deer used shelterwoods the most $(50.9 \pm$ 9.7 [1 $\mathrm{SE}])$, followed by thinnings $(28.9 \pm 6.9[1 \mathrm{SE}])$ and reserves $(18.7 \pm 4.3[1 \mathrm{SE}])$. Given the variation in estimated deer activity densities, we expected some of our sites to be subject to high potential deer herbivory pressure. Our exclosure experiment revealed that harvest strategy and deer browsing did indeed have impacts on some vegetation classes and that the effects varied by season.

3.1. Impacts on Forest Plant Groups. Dominant plants, based on percent cover, included white pine for the conifer plant group; birches, oaks, and maples for the hardwoods; Rubus spp., blueberry (Vaccinium spp.), and mountain laurel for the shrubs; and Canada mayflower, wild sarsaparilla, and 
TABLE 1: Three-factor repeated measures ANOVA used to examine the mean browse index and percent cover for conifer, forb, shrub, and hardwood plant groups at YMF. Independent factors were harvest strategy and exclosure presence, and the repeated factor was month. Only the main effects are presented.

\begin{tabular}{|c|c|c|c|c|c|c|c|}
\hline \multicolumn{8}{|c|}{ Conifers } \\
\hline \multicolumn{4}{|c|}{ Browse index } & \multicolumn{4}{|c|}{ Percent cover } \\
\hline Source & $\mathrm{DF}$ & $F$ & $P$ & Source & DF & $F$ & $P$ \\
\hline Harvest strategy & 2 & 1.47 & 0.251 & Harvest strategy & 2 & 1.05 & 0.366 \\
\hline Exclosure & 1 & 1.07 & 0.312 & Exclosure & 1 & 0.01 & 0.908 \\
\hline Residuals & 168 & & & Residuals & 120 & & \\
\hline \multicolumn{8}{|c|}{ Forbs } \\
\hline \multicolumn{4}{|c|}{ Browse index } & \multicolumn{4}{|c|}{ Percent cover } \\
\hline Harvest strategy & 2 & 1.19 & 0.323 & Harvest strategy & 2 & 2.85 & 0.080 \\
\hline Exclosure & 1 & 1.84 & 0.188 & Exclosure & 1 & 0.03 & 0.858 \\
\hline Residuals & 168 & & & Residuals & 120 & & \\
\hline \multicolumn{8}{|c|}{ Shrubs } \\
\hline \multicolumn{4}{|c|}{ Browse index } & \multicolumn{4}{|c|}{ Percent cover } \\
\hline Harvest strategy & 2 & 13.90 & $<0.001^{*}$ & Harvest strategy & 2 & 27.26 & $<0.001^{*}$ \\
\hline Exclosure & 1 & 36.03 & $<0.001^{*}$ & Exclosure & 1 & 0.01 & 0.956 \\
\hline Residuals & 168 & & & Residuals & 120 & & \\
\hline \multicolumn{8}{|c|}{ Hardwoods } \\
\hline \multicolumn{4}{|c|}{ Browse index } & \multicolumn{4}{|c|}{ Percent cover } \\
\hline Harvest strategy & 2 & 0.76 & 0.476 & Harvest strategy & 2 & 8.22 & $0.002^{*}$ \\
\hline Exclosure & 1 & 18.97 & $<0.001^{*}$ & Exclosure & 1 & 0.05 & 0.823 \\
\hline Residuals & 168 & & & Residuals & 120 & & \\
\hline
\end{tabular}

${ }^{*}$ Denotes significant results $(P \leq 0.05)$.

starflower for the forbs. ANOVA revealed that deer herbivory (presence or absence of an exclosure) and harvest strategy did not have a significant effect on conifers and forbs (as measured by browse index or percent cover, Table 1). ANOVA revealed that deer herbivory did not have a significant effect on shrub percent cover regardless of harvest strategy (Table 1). Harvesting strategy, however, had a significant effect on shrub percent cover. Tukey pairwise comparisons indicated that shelterwood harvests had higher shrub percent covers than thinnings or reserves (Figure 1(a)). ANOVA revealed that harvest strategy had an effect on shrub browse index. Tukey pairwise comparisons indicated that shelterwood and thinning harvest strategies had higher browse indices than reserves (Figure 1(a)). ANOVA revealed that deer herbivory had an effect on shrub browse index (Table 1). Tukey analysis indicated that shelterwood and thinning harvest strategies caused higher shrub browse indices than reserves (Figure 1(a)). ANOVA revealed that deer herbivory had a significant impact on the hardwood browse index, but harvest strategy did not (Table 1). Tukey pairwise comparisons suggested that deer impacts on hardwoods were significant in all three forest harvest types (Figure 1(b)). ANOVA revealed that only harvest strategy had an effect on the percent cover of hardwood species, while deer herbivory did not (Table 1). Tukey pairwise comparisons suggested that shelterwood harvests had higher percent covers than thinning or reserves (Figure 1(b)).

\subsection{Mechanism of Impact: Thermal Settling Stimulus or Deer Activity Density}

3.2.1. Thermal Environment versus Deer Activity Density. Regression analysis revealed a significant relationship between heat flux (TE) and deer activity density for the summer season $\left(F_{1,12}=14.04, R^{2}=0.54, P=0.003\right)$. Deer activity density varied with $T E$ values according to the relationship: deer $\mathrm{km}^{-2}=1.61 \times 10^{-32} \times T E^{22.54}$, meaning that warmer sites had higher deer activity density estimates than cooler sites (Figure 2(a)). This significant effect was derived after removing one outlier that had an unusually low estimated $T E$ value $\left(24.77 \mathrm{Wm}^{-2}\right)$ given a high deer activity density estimate of 67 deer $\mathrm{km}^{-2}$. The estimated TE value was $15.5 \%$ lower than the mean $T E$ value of all sites $\left(29.33 \mathrm{Wm}^{-2}\right)$. This site is a reserve located at the border of YMF and in close proximity to several houses, thereby having greater habitat fragmentation than the surrounding forest matrix, possibly explaining the relatively high deer activity density estimate for a relatively cool site. Regression analysis revealed a moderately significant relationship between $T E$ and estimated deer activity density for the fall season $\left(F_{2,12}=3.17, R^{2}=0.35, P=0.078\right)$ in which deer activity density varied with $T E$ values according to the relationship: deer $\mathrm{km}^{-2}=0.13(T E)^{2}-13.12(T E)+326.64$, meaning that warmer and cooler sites had higher deer density activity 


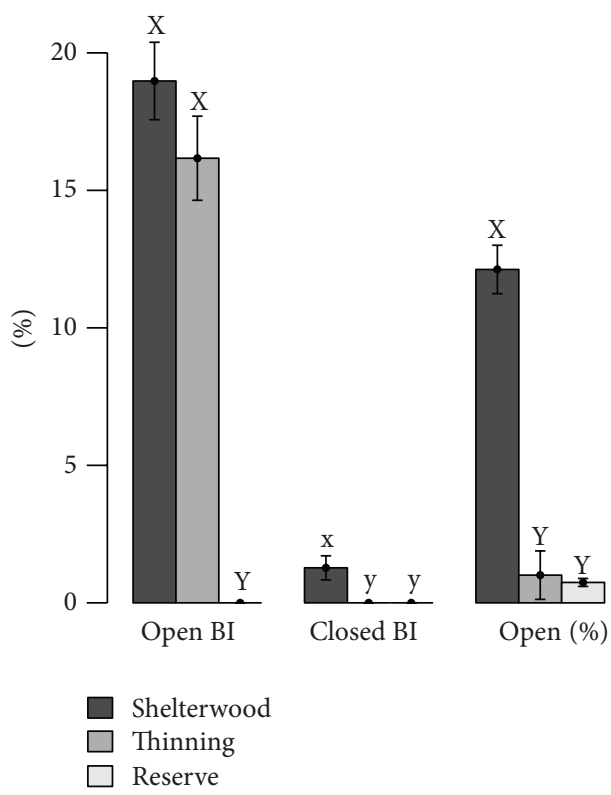

(a)
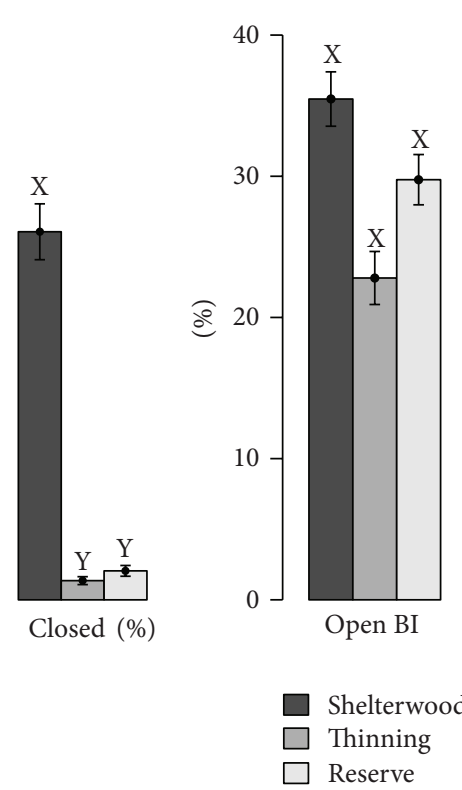

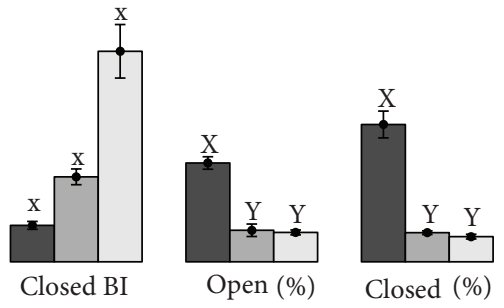

(b)

Figure 1: Browse index (left, BI) and percent cover (right, \%) for the shrub plant group (a) and hardwood plant group (b) at YMF among open and closed plots by harvest strategy. Upper case versus lower case letters above standard error bars indicate values that are statistically different between open and closed plots by Tukey pairwise comparisons. Unlike letters of the same case indicate values that are statistically different between harvest strategies using Tukey pairwise comparisons.

estimates than intermediate sites (Figure 2(b)). There were no significant relationships between $T E$ and deer activity density for the winter and spring seasons (Figures 2(c) and $2(d))$.

3.2.2. Thermal Environment versus Browse Index. Regression revealed a moderately significant relationship between $T E$ and browse index for the summer season $\left(F_{1,13}=3.49\right.$, $R^{2}=0.21$, and $\left.P=0.085\right)$. Browse index varied with $T E$ values according to the relationship: browse index = $1.65 \times 10^{-5} \times T E^{2.49}$, meaning that warmer sites had higher browse indices than cooler sites (Figure 3(a)). Regression revealed a moderately significant relationship between $T E$ and browse index for the fall season $\left(F_{1,12}=2.84, R^{2}=\right.$ 0.32 , and $P=0.098)$. Browse index was described by the relationship: browse index $=0.0005(T E)^{2}-0.042(T E)+1.054$, meaning that warmer and cooler sites had higher browse indices than intermediate sites (Figure 3(b)). None of the models describing the relationship between TE and browse index were significant for winter and spring (Figures 3(c) and $3(d))$.

3.2.3. Deer Activity Density versus Browse Index. Regression revealed a moderately significant relationship between deer activity density estimates and browse index for the winter season $\left(F_{2,12}=3.12, R^{2}=0.34\right.$, and $\left.P=0.081\right)$. Browse index varied with deer activity density according to the relationship: browse index $=-3.127 \times 10^{-5}(\text { deer density })^{2}+$ $4.38 \times 10^{-3}$ (deer density) +0.075 , meaning that locations with lowest and highest estimates of deer activity density had lower browse indices than locations with intermediate deer densities (Figure 4(c)). There were no significant relationships between deer density and browse index for the summer, fall, or spring seasons (Figures 4(a), 4(b), and 4(d)).

\section{Discussion}

The goal of this study was to evaluate, using an exclosure experiment superimposed on a landscape-scale comparison of forest harvest strategies for regenerating oak, whether thermal settling stimulus or deer activity density affects deer browsing impact on a northeastern forest. The rationale for the study (sensu [13]) was that if deer activity density or thermal settling stimulus was an important determinant of deer impacts on forests, then these variables should explain a high degree of variation in browse impact and hence potential forest regeneration failure. We examined the impact on four major forest plant groups (forbs, shrubs, conifers, and hardwoods). The plant species comprising forbs, shrubs, and hardwoods were well suited for examinations of deer impacts because deer prefer to consume these species in the northeast, whereas the conifer group, primarily white pine, is not preferred by deer $[2,13]$. All plant groups sampled were less than 1.2 meters tall and hence at risk of browsing impact because they fell within the optimal reach of deer [26, 27]. Comparisons of exclosure and open plots revealed that deer did indeed browse in the harvest areas, but impact varied seasonally.

We found thermal settling stimulus to be related to estimated deer activity density in the summer and fall seasons 


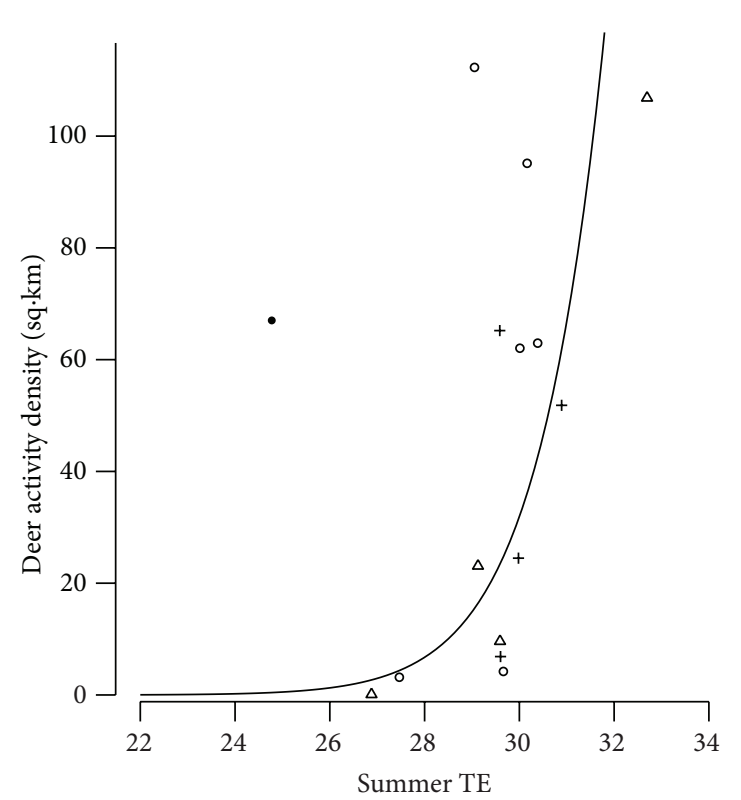

(a)

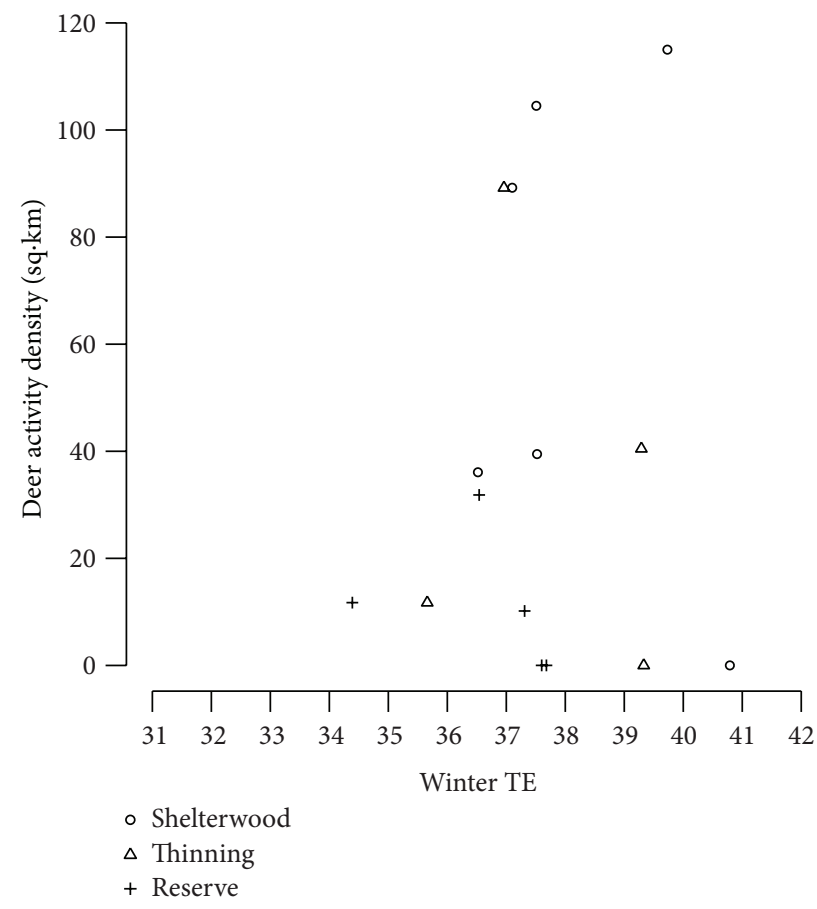

(c)

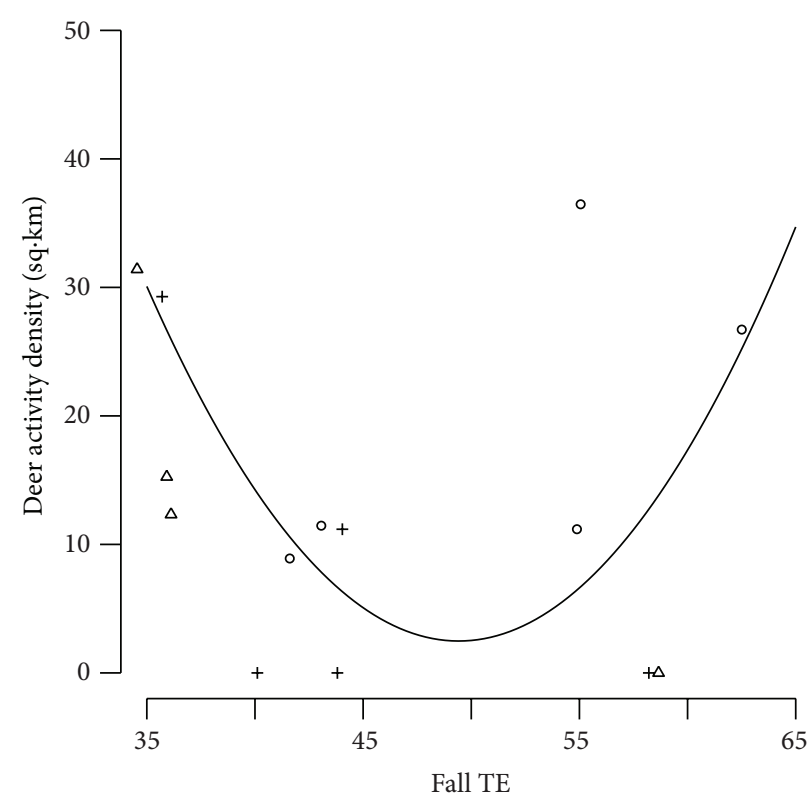

(b)

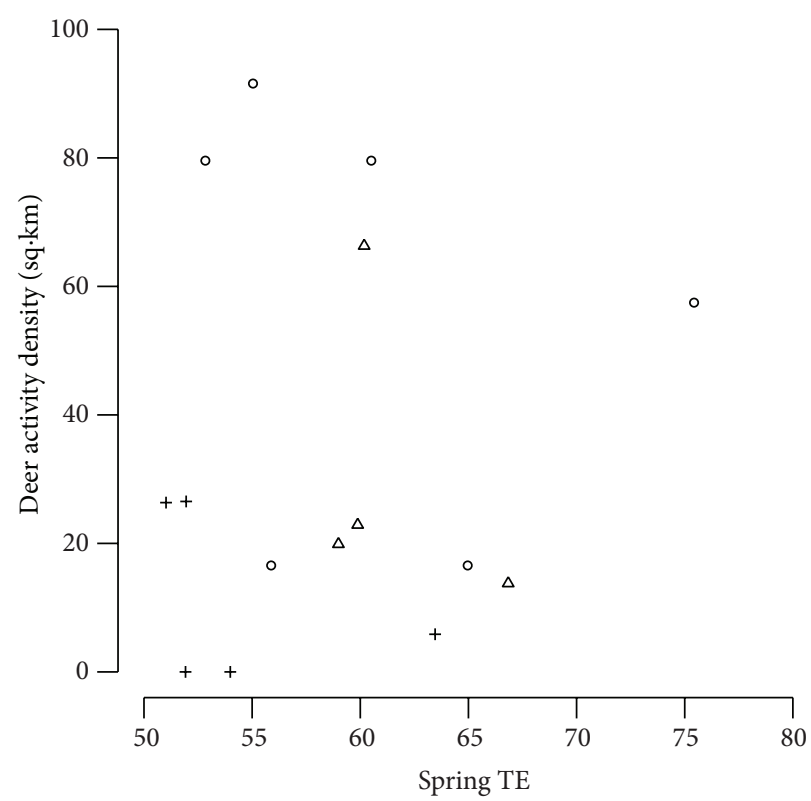

- Shelterwood

$\Delta$ Thinning

+ Reserve

Figure 2: Relationship between the thermal environment (TE) and deer activity density at YMF for the (a) summer (May-August), (b) fall (September-October), (c) winter (November-January), and (d) spring seasons (February-March). Regression lines are provided when significant models were produced. The black point in panel (a) indicates an outlier that was removed from analysis.

but not during the winter and spring. Even though thermal settling stimulus and deer activity density were correlated in some seasons, the resulting deer impacts could not be explained by both variables equally. Thermal settling stimulus appeared to be a statistically better predictor of deer browse impact than deer activity density during summer and fall. Because trees are leafed out during the summer and fall months creating shade throughout the landscape, $T E$ values are generally more thermally neutral across all habitat types during the summer and fall seasons, with the exception of a few sites (representing all three forest harvest strategies) during the fall. Daily feeding time for many ungulates is determined by the thermal environment $[22,23]$; therefore, thermal settling stimulus is likely a better 


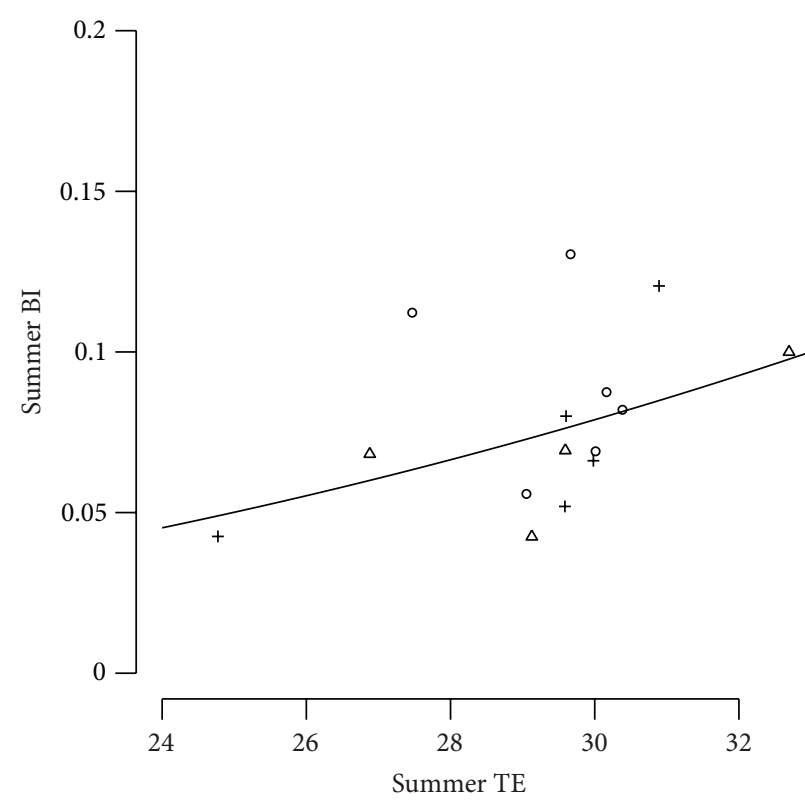

(a)

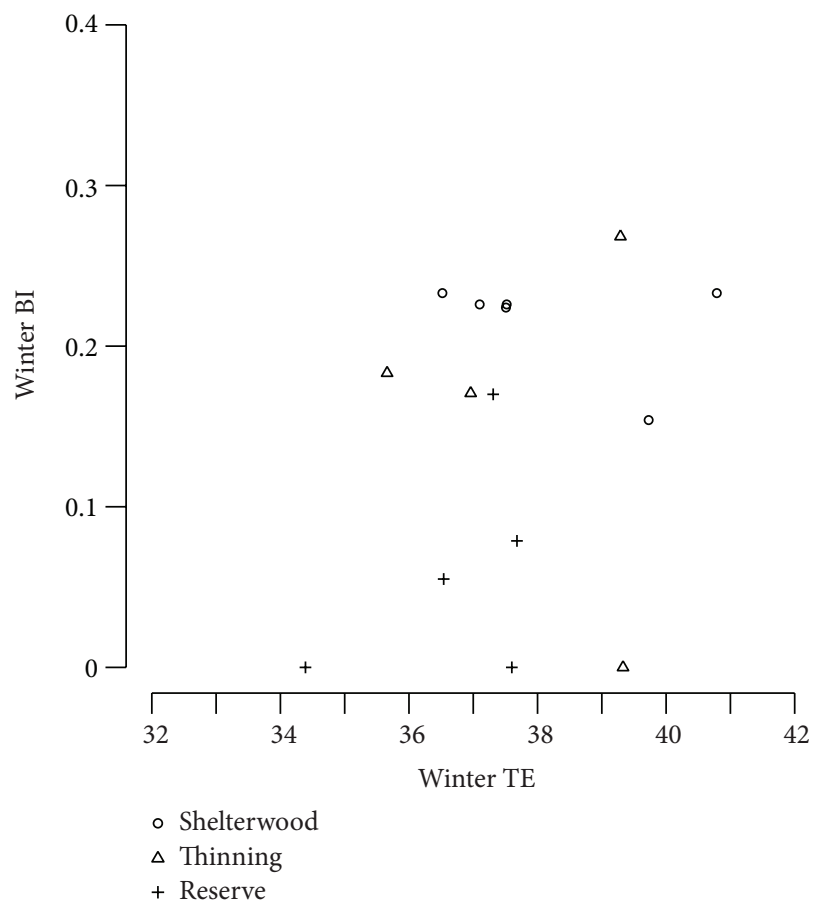

(c)

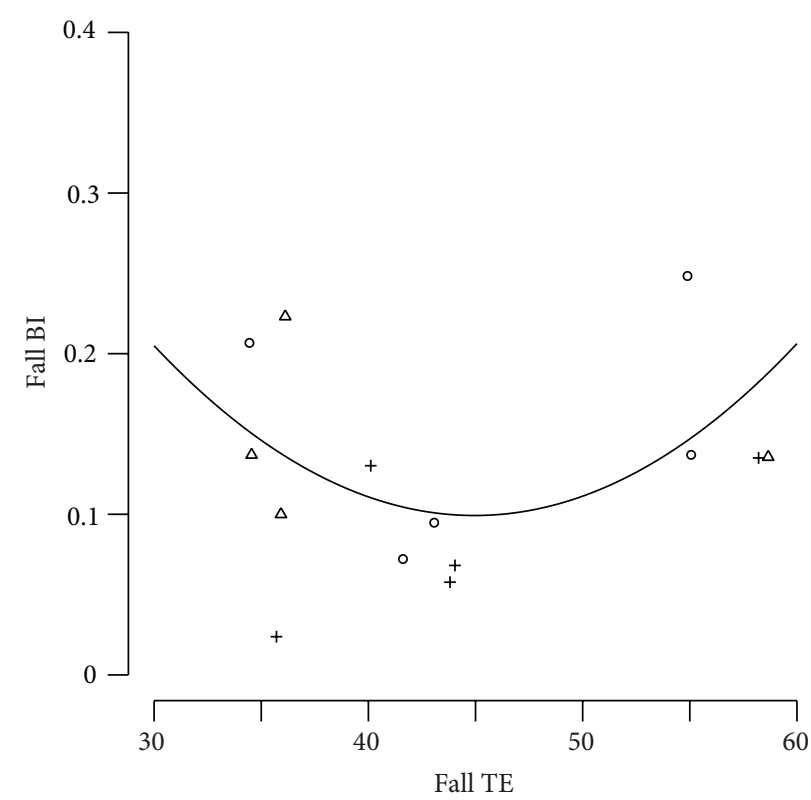

(b)

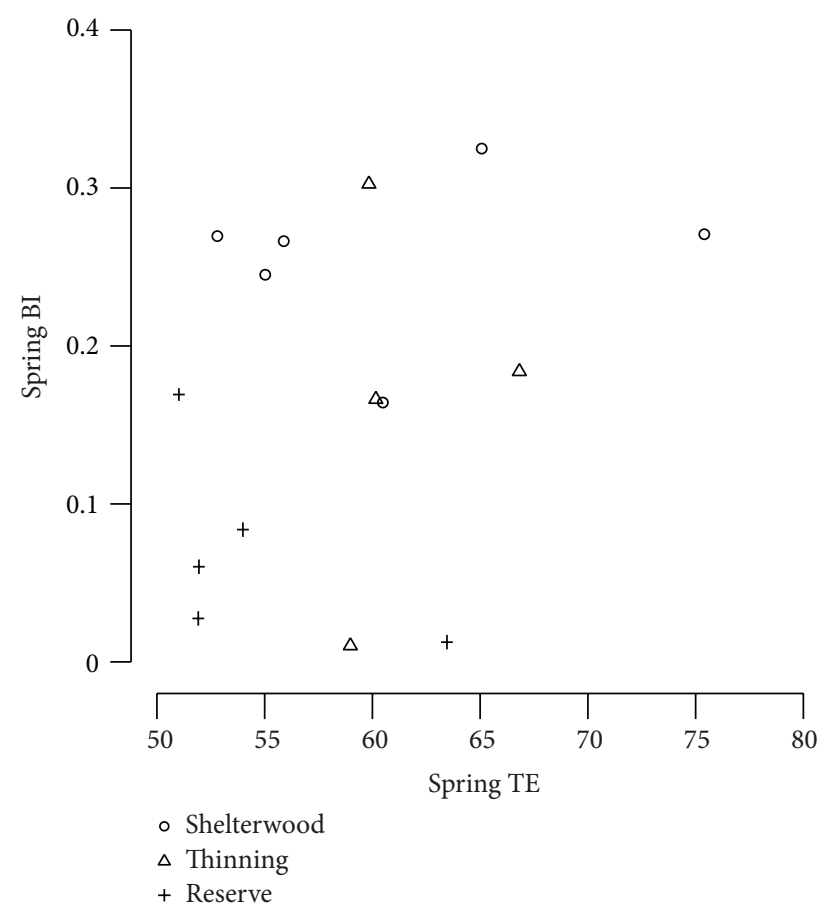

(d)

FIGURE 3: Relationship between the thermal environment (TE) and browse index (BI) at YMF for (a) the summer (May-August), (b) fall (September-October), (c) winter (November-January), and (d) spring seasons (February-March). Regression lines are provided when significant models were produced.

predictor of browsing impact during the summer and fall because the more sheltered landscape gives deer a greater scope to reduce thermal stress, allowing them to devote more time to browsing in thermally attractive areas, even when at lower densities. That is, while perhaps at lower densities, increased per capita browsing effort by deer in thermally favorable habitat can result in as high of an impact or higher impact than that realized when deer are under higher densities in less thermally favorable habitat. Although these results may be density dependent and territorial behavior by white-tailed deer could cause some deer to disperse into suboptimal habitats, deer should still concentrate their foraging activity in places that are relatively more favorable. Indeed, thermal settling stimulus did not predict browsing 


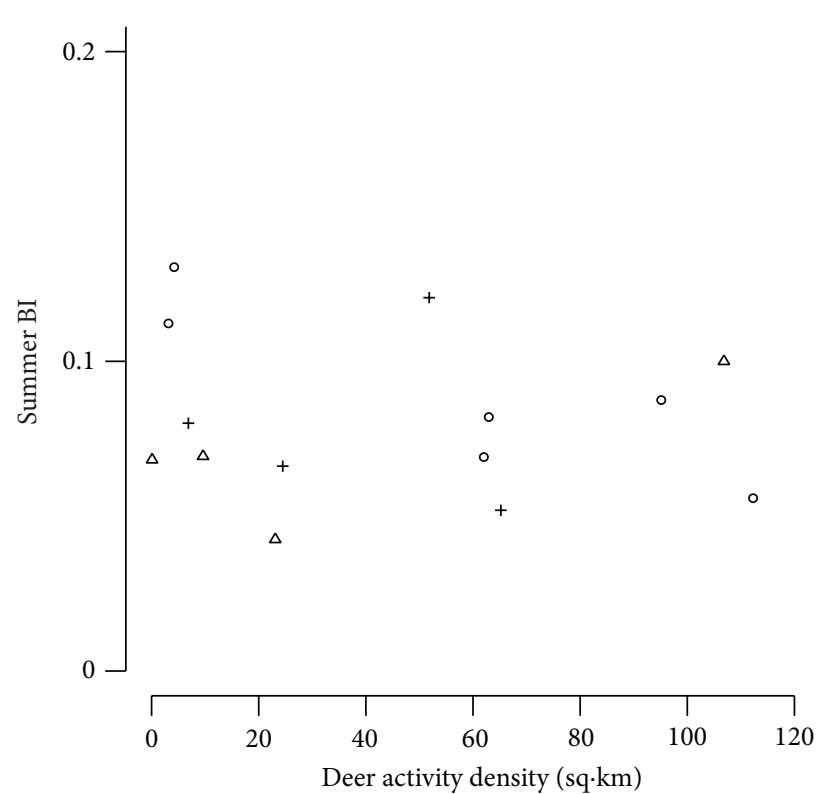

(a)

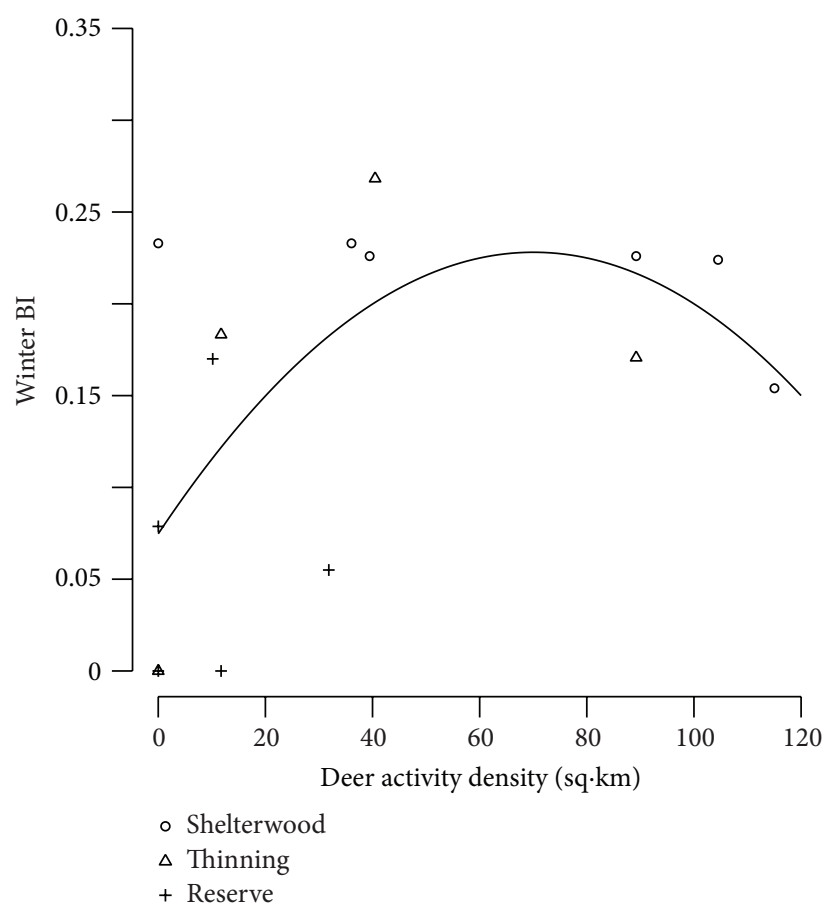

(c)

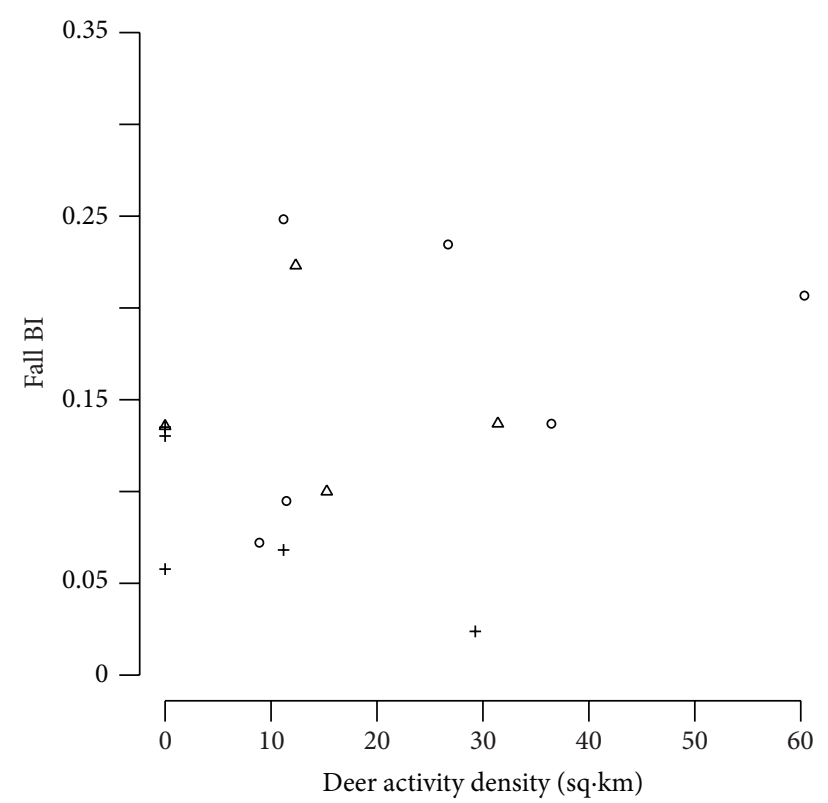

(b)

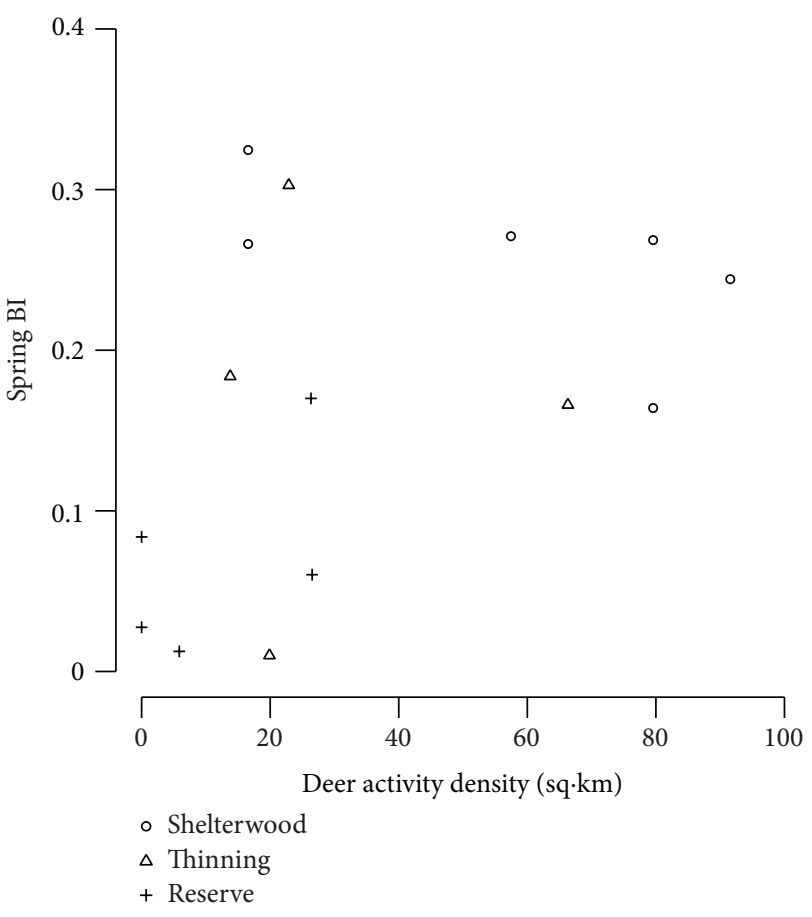

(d)

FIGURE 4: Relationship between activity deer density and browse index (BI) at YMF for (a) the summer (May-August), (b) fall (SeptemberOctober), (c) winter (November-January), and (d) spring seasons (February-March). Regression lines are provided when significant models were produced.

impact as well as deer activity density in the cooler winter months due to a more thermally homogeneous landscape in which deer are more exposed to weather conditions. More exposure to harsh weather conditions likely resulted in a lower scope for deer to mediate browsing behavior based on the thermal environment. This, combined with the fact that deer metabolism slows during the winter leading to concentrated foraging on select plant groups [35], results in areas with higher deer activity densities having higher browsing impacts because there are fewer thermally attractive options for deer to choose to spend time foraging in and fewer species that deer browse upon. Despite the correlation between deer activity density and thermal settling stimulus, the two variables differentially determined impacts, because 
plots within a particular harvest strategy had similar TE values but more variable deer activity densities. For example, shelterwood $T E$ values ranged from 27.5 to $30.4 \mathrm{Wm}^{-2}$ in the summer, while deer activity densities spanned almost the entire range of observed densities for all harvest types (refer to Figure 2). This suggests that thermal environment may be a consistently better predictor of variation in deer impact across the forested landscape at YMF than deer activity density. These results are consistent with earlier case studies about settling stimulus and deer impacts in forest environments (see $[15,16,18]$ ).

We did not investigate the possible impact deer have on height, growth, and species composition in hardwood forests. However, despite ample evidence of browse impact on hardwoods in all three harvest types throughout the study area, we could not detect adverse effects on forest regeneration measured as percent cover (refer to Figure 1). Similarly, deer impacted shrubs in shelterwood and thinning harvests, but the impact did not affect ground cover.

The conventional strategy to mitigate the effects of deer herbivory on the landscape is culling deer populations to lower deer abundances, thus decreasing the browsing impacts deer have on plant communities $[1,4,5]$. This strategy would only be warranted when deer density is strongly positively related to browse impact. Although this may be the case under certain landscape contexts, we found that deer density was not generally the cause of browse impact at YMF. Indeed, intermediate deer densities in some cases led to more browsing impact, but herbivory did not necessarily inhibit forest regeneration capacity or alter understory plant communities. This was especially the case when a given site's thermal conditions led to less favorable deer thermal settling stimulus. This suggests that the effects deer have on understory plant communities can be mediated by the thermal environment whereby deer concentrate foraging activity in sites with favorable thermal energy exchanges with the environment in order to manage tradeoffs between eating and maintaining thermal homeostasis [23].

There is increasing awareness that high deer abundances do not necessarily translate into diminished forest regeneration capacity or detrimental impacts on forest understory communities [12, 13, 38]. Indeed, Russell et al. [38] acknowledge that although deer density is a contributing factor in determining browsing impact on vegetative communities, little is known about contributing factors that may modify these effects across landscapes. Landscape-scale evaluations of deer impacts in western Connecticut revealed that relationships between deer abundance and plant species abundance or diversity or the ability of forests to regenerate varied considerably with other landscape-scale features such as land use and management that promote deer impacts at local scales [13]. Similarly, Hurley et al. [12] found that although deer abundance explained $19 \%$ of the variation in native herb cover across Indiana, models that accounted for deer abundance and the interspersion and juxtaposition of perennial forb habitat explained $84 \%$ of the variation in native herb cover. This indicates that landscape context independently of deer abundance can have substantial effects on deer browsing impact. Our study quantified thermal aspects of that landscape context to reveal that spatial variation in biophysical conditions among different forest cover types juxtaposed with food availability across the landscape is a stronger predictor of browsing impact on the forest than merely deer activity densities. Moreover, because thermal conditions of different harvests changed seasonally, there was much context dependency in browse impact throughout the year. Consequently, lowering deer abundances alone is unlikely to be the single best strategy for mitigating browse impacts.

Most deer impacts to woody browse regeneration occur during winter. Our study indicates this as browse impact was generally lower during the warmer summer months (Figures 3 and 4). Deer generally prefer different environments depending on weather conditions. For example, deer may seek warm, sunny environments on colder days and forested areas during wind events. Our study revealed that shelterwood harvests are likely the most susceptible to deer impacts because of ample understory browse production in combination with warm thermal conditions that make these harvests attractive to deer. Many shelterwoods are also in close proximity to more heavily forested sites, giving them quick reprieve from adverse conditions, thereby creating an environment conducive to deer spending time browsing in. Our research shows that forest management may mediate deer impacts by balancing production of regeneration with deer impact using forest thinning harvest strategies. Even so, our research shows that the presence of deer on the landscape may not necessarily always lead to impaired regeneration.

\section{Conclusions}

Understanding the underlying mechanisms determining spatial variation in deer browsing behavior is key to making deer management decisions aimed at forest regeneration. The conventional strategy is to directly alter deer densities via hunting or culling to mitigate deer herbivory effects $[1,4,5]$. This presumes that deer density consistently explains the majority of variation in deer impacts [13]. We found minimal evidence that deer activity density consistently affects forest plant communities within YMF. When density was a factor, it was intermediate rather than high densities that resulted in the greatest impact. A greater understanding of deer habitat selection and foraging behavior with respect to biophysical habitat components may give us a more nuanced approach to mitigating the effects of deer herbivory in the future.

Instead of using conventional deer management strategies to meet forest regeneration objectives, it may be more effective to implement forest management strategies to address the effects deer herbivory has on forest regeneration. We found that thermal settling stimulus, determined by the thermal energy exchange between deer and the thermal environment, was a contributing factor in determining deer browsing impact. The implication is that forest management can mitigate browse impact by implementing harvest strategies that alter forest microhabitats and thereby modify diurnal and seasonal temperature fluctuations in ways that make 
the forest sites less conducive to deer presence and hence impact. For example, intensive harvesting strategies generally create warmer environments during the summer months and more variable environments during the fall months, with the attendant seasonal trend in browsing impact [39]. Less intense harvesting strategies generally create cooler and more variable thermal environments and lower browse indices (see Figure 3). It is noteworthy that heavily harvested areas tend to have the highest plant productivity, a contributing factor to higher browse index values. Nevertheless, when forest regeneration is a management objective, implementing harvests that minimize the creation of warmer thermal environments in the surrounding land matrix can reduce or mitigate browsing damage even in areas with high browse abundance.

\section{Conflict of Interests}

None of the authors are affiliated with any commercial identities mentioned in this paper; thus, there is no conflict of interests in this paper.

\section{Acknowledgments}

The authors thank the Carpenter-Sperry Research Fund and the Schiff Fund for their financial support. The Landscape Management System Laboratory generously provided lab facilities. They thank the Yale Myers Forest for allowing them to conduct their study on their property. They thank R. Campbell for providing valuable information regarding the logistics of the forest. They thank M. Ashton, E. Hooper, K. Mack, H. Bement, T. Usrell, J. Miller, C. Donihue, H. Glick, K. McLean, and A. Trainor for comments and discussion.

\section{References}

[1] W. S. Alverson, D. M. Waller, and S. L. Solheim, "Forests too deer: edge effects in Northern wisconsin," Conservation Biology, vol. 2, no. 4, pp. 348-358, 1988.

[2] W. M. Healy, "Influence of deer on the structure and composition of oak forests in central Massachusetts," in The Science of Overabundance: Deer Ecology and Population Management, W. J. McShea, H. B. Underwood, and J. H. Rappole, Eds., Smithsonian Institution Press, Washington, DC, USA, 1997.

[3] E. W. Beals, G. Cottam, and R. J. Vogl, "Influence of deer on vegetation of the Apostle Islands, Wisconsin," The Journal of Wildlife Management, vol. 24, no. 1, pp. 68-80, 1960.

[4] S. B. Horsley, S. L. Stout, and D. S. DeCalesta, "White-tailed deer impact on the vegetation dynamics of a northern hardwood forest," Ecological Applications, vol. 13, no. 1, pp. 98-118, 2003.

[5] T. P. Rooney and D. M. Waller, "Direct and indirect effects of white-tailed deer in forest ecosystems," Forest Ecology and Management, vol. 181, no. 1-2, pp. 165-176, 2003.

[6] J. F. Franklin, T. A. Spies, R. V. Pelt et al., "Disturbances and structural development of natural forest ecosystems with silvicultural implications, using Douglas-fir forests as an example," Forest Ecology and Management, vol. 155, no. 1-3, pp. 399-423, 2002.
[7] A. F. Hough, "A twenty-year record of understory vegetational change in a Virgin Pennsylvania Forest," Ecology, vol. 46, no. 3, pp. 370-373, 1965.

[8] N. G. Tilghman, "Impacts of white-tailed deer on forest regeneration in northwestern Pennsylvania," Journal of Wildlife Management, vol. 53, no. 3, pp. 524-532, 1989.

[9] D. S. DeCalesta, "Deer and ecosystem management," in The Science of Overabundance: Deer Ecology and Population Management, W. J. McShea, H. B. Underwood, and J. H. Rappole, Eds., pp. 267-297, Smithsonian Institution Press, Washington, DC, USA, 1997.

[10] W. J. McShea, H. B. Underwood, and J. H. Rappole, "Deer management and the concept of overabundance," in The Science of Overabundance: Deer Ecology and Population Managment, W. J. McShea, H. B. Underwood, and J. H. Rappole, Eds., pp. 1-7, Smithsonian Institution Press, Washington, DC, USA, 1997.

[11] O. J. Schmitz and A. R. E. Sinclair, "Rethinking the role of deer in forest ecosystem dynamics," in The Science of Overabundance: Deer Ecology and Population Management, W. J. McShea, H. B. Underwood, and J. H. Rappole, Eds., pp. 201-223, Smithsonian Institution Press, Washington, DC, USA, 1997.

[12] P. M. Hurley, C. R. Webster, D. J. Flaspohler, and G. R. Parker, "Untangling the landscape of deer overabundance: reserve size versus landscape context in the agricultural Midwest," Biological Conservation, vol. 146, no. 1, pp. 62-71, 2012.

[13] A. C. Rutherford and O. J. Schmitz, "Regional-scale assessment of deer impacts on vegetation within western Connecticut, USA," Journal of Wildlife Management, vol. 74, no. 6, pp. 1257$1263,2010$.

[14] A. Leopold, Game Management, Charles Scribner's Sons, New York, NY, USA, 1933.

[15] F. Reimoser and H. Gossow, "Impact of ungulates on forest vegetation and its dependence on the silvicultural system," Forest Ecology and Management, vol. 88, no. 1-2, pp. 107-119, 1996.

[16] F. Reimoser, "Steering the impacts of ungulates on temperate forests," Journal for Nature Conservation, vol. 10, no. 4, pp. 243252, 2003.

[17] S. Reimoser, E. Partl, F. Reimoser, and S. Vospernik, "Roedeer habitat suitability and predisposition of forest to browsing damage in its dependence on forest growth-Model sensitivity in an alpine forest region," Ecological Modelling, vol. 220, no. 18, pp. 2231-2243, 2009.

[18] E. Partl, V. Szinovatz, F. Reimoser, and J. Schweiger-Adler, "Forest restoration and browsing impact by roe deer," Forest Ecology and Management, vol. 159, no. 1-2, pp. 87-100, 2002.

[19] S. Vospernik and S. Reimoser, "Modelling changes in roe deer habitat in response to forest management," Forest Ecology and Management, vol. 255, no. 3-4, pp. 530-545, 2008.

[20] S. D. Côté, T. P. Rooney, J.-P. Tremblay, C. Dussault, and D. M. Waller, "Ecological impacts of deer overabundance," Annual Review of Ecology, Evolution, and Systematics, vol. 35, pp. 113147, 2004.

[21] J.-P. Tremblay, J. Huot, and F. Potvin, "Density-related effects of deer browsing on the regeneration dynamics of boreal forests," Journal of Applied Ecology, vol. 44, no. 3, pp. 552-562, 2007.

[22] G. E. Belovsky, "Optimal activity times and habitat choice of moose," Oecologia, vol. 48, no. 1, pp. 22-30, 1981.

[23] O. J. Schmitz, "Thermal constraints and optimization of winter feeding and habitat choice in white-tailed deer," Holarctic Ecology, vol. 14, no. 2, pp. 104-111, 1991. 
[24] D. M. Waller and W. S. Alverson, "The white-tailed deer: a keystone herbivore," Wildlife Society Bulletin, vol. 25, no. 2, pp. 217-226, 1997.

[25] D. B. Kittredge and P. M. S. Ashton, "Impact of deer browsing on regeneration in mixed stands in southern New England," Northern Journal of Applied Forestry, vol. 12, no. 3, pp. 115-120, 1995.

[26] M. A. Barrett and P. Stiling, "Effects of Key deer herbivory on forest communities in the lower Florida Keys," Biological Conservation, vol. 129, no. 1, pp. 100-108, 2006.

[27] R. M. A. Gill, "A review of damage by mammals in north temperate forests: 1. Deer," Forestry, vol. 65, no. 2, pp. 145-169, 1992.

[28] T. P. Rooney, R. J. McCormick, S. L. Solheim, and D. M. Waller, "Regional variation in recruitment of hemlock seedlings and saplings in the upper Great Lakes, USA," Ecological Applications, vol. 10, no. 4, pp. 1119-1132, 2000.

[29] T. P. Rooney, S. L. Solheim, and D. M. Waller, "Factors affecting the regeneration of northern white cedar in lowland forests of the Upper Great Lakes region, USA," Forest Ecology and Management, vol. 163, no. 1-3, pp. 119-130, 2002.

[30] L. Eberhardt and R. C. V. Etten, "Evaluation of the pellet group count as a deer census method," The Journal of Wildife Management, vol. 20, no. 1, pp. 70-74, 1956.

[31] D. J. Neff, "The pellet-group count technique for big game trend, census, and distribution: a review," The Journal of Wildlife Management, vol. 32, no. 3, pp. 597-614, 1968.

[32] D. M. Forsyth, R. J. Barker, G. Morriss, and M. P. Scroggie, "Modeling the relationship between fecal pellet indices and deer density," Journal of Wildlife Management, vol. 71, no. 3, pp. 964970, 2007.

[33] F. F. C. Marques, S. T. Buckland, D. Goffin et al., "Estimating deer abundance from line transect surveys of dung: sika deer in Southern Scotland," Journal of Applied Ecology, vol. 38, no. 2, pp. 349-363, 2001.

[34] W. P. Porter and D. M. Gates, "Thermodynamic equilibria of animals with environment," Ecological Monographs, vol. 39, no. 3, pp. 227-244, 1969.

[35] A. N. Moen, "Seasonal changes in heart rates, activity, metabolism, and forage intake of white-tailed deer," The Journal of Wildlife Management, vol. 42, no. 4, pp. 715-738, 1978.

[36] A. N. Moen, "Surface temperatures and radiant heat loss from white-tailed deer," The Journal of Wildlife Management, vol. 32, no. 2, pp. 338-344, 1968.

[37] W. M. Tzilkowski and G. L. Storm, "Detecting change using repeated measures analysis-white-tailed deer abundance at Gettysburg National Military Park," Wildlife Society Bulletin, vol. 21, no. 4, pp. 411-414, 1993.

[38] F. L. Russell, D. B. Zippin, and N. L. Fowler, "Effects of whitetailed deer (Odocoileus virginianus) on plants, plant populations and communities: a review," American Midland Naturalist, vol. 146, no. 1, pp. 1-26, 2001.

[39] R. T. Brooks and T. D. Kyker-Snowman, "Forest floor temperature and relative humidity following timber harvesting in southern New England, USA," Forest Ecology and Management, vol. 254, no. 1, pp. 65-73, 2008. 

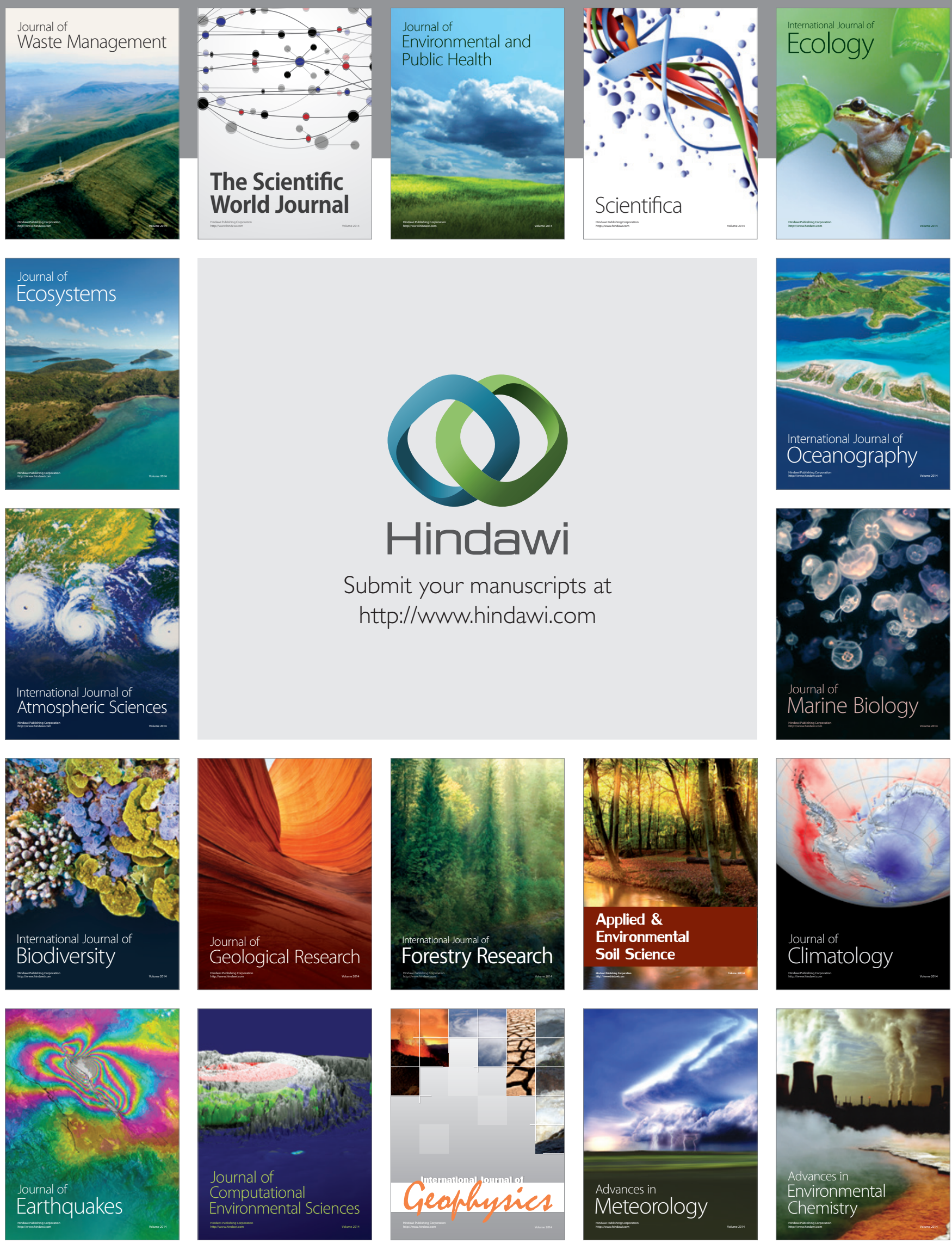